\title{
Diabetic Macular Oedema and the Importance of Vascular Endothelial Growth Factor Therapies in its Treatment
}

\author{
Sebastian Wolf \\ Director and Chief Physician, Department of Ophthalmology, Inselspital, University Hospital and University Bern, Bern, Switzerland
}

\begin{abstract}
Diabetic macular oedema (DMO) is a major cause of blindness that has an increasing prevalence associated with the general population in diabetes worldwide. In DMO, increased expression of factors including vascular endothelial growth factor (VEGF) disrupts the bloodretina barrier causing leakage and accumulation of extracellular fluid in the macula with resultant loss of vision. Focal and grid laser photocoagulation has been used to treat DMO for many years, but can cause scarring and atrophy. Vitrectomy is also associated with undesirable effects and its use is mainly confined to tractional DMO cases. Intravitreal steroids have been used successfully but are associated with increased intraocular pressure and cataracts. The intravitreal anti-VEGF treatments have shown improved vision and reduced macular thickness in DMO with good tolerability. Among these, ranibizumab is the only treatment approved in the US and EU for this indication. Its use is supported by extensive clinical trials in which it was shown to be effective with or without laser treatment. Ranibizumab is cost-effective and is likely to have a continuing role in DMO therapy.
\end{abstract}

\section{Keywords}

Diabetic macular oedema, retinal pathology, anti-vascular endothelial growth factor, ranibizumab

Disclosure: Sebastian Wolf is on advisory boards, has served as a consultant and a speaker for Allergan, Bayer, Heidelberg Engineering, Molecular Partners, Novartis, Roche, and Optos. Acknowledgements: Editorial assistance was provided by James Gilbart at Touch Medical Media.

Received: 17 October 2013 Accepted: 6 December 2013 Citation: European Ophthalmic Review, 2014;8(1):Epub ahead of print DOI: 10.17925/EOR.2014.08.01.i

Correspondence: Sebastian Wolf, Direktor und Chefarzt, INSELSPITAL, Universitätsspital Bern, Universitätsklinik für Augenheilkunde, 3010 Bern, Switzerland.

E: Sebastian.Wolf@insel.ch

Support: The publication of this article was supported by Novartis. The views and opinions expressed are those of the authors and not necessarily those of Novartis.

Diabetic macular oedema (DMO) is a major cause of blindness worldwide and its incidence is increasing due to the greater numbers of people with diabetes. ${ }^{1-4}$ The disease is a result of changes in retinal capillaries that leak and changes in the retinal pigment epithelium causing macular thickening, oedema and poor eyesight, leading to vision loss if left untreated. ${ }^{5,6}$ DMO is particularly serious due to its onset affecting a young/middleaged age group and disabling them during their productive working lives. $^{2}$ Laser photocoagulation treatments have been the mainstay of treatment over the past few decades, but this can be destructive and destroys photoreceptors around the retinal areas affected. Steroids given intravitreally are also used to treat $\mathrm{DMO}$, but these can have undesirable side effects, such as cataracts and increased intraocular pressure (IOP). ${ }^{\text {. }}$ Early DMO is associated with substantially increased vascular endothelial growth factor (VEGF) secretion, and treatments that block VEGF, particularly ranibizumab, have shown significant improvements vision in patients with DMO compared with laser treatment and shows good long-term safety.,9, This medication is proving to be a valuable option in DMO treatment. This review will outline the pathology and burden of $\mathrm{DMO}$, its associations with both types I and II diabetes and different approaches to treatment.

\section{The Prevalence and Burden of Diabetic Macular Oedema}

Prevalence estimates of DMO from numerous studies vary widely, largely as a result of differing populations included and different definitions of
DMO. Epidemiological data on DMO are sparse and reported incidence varies between countries. ${ }^{2}$ A systematic review of 359 studies found the prevalence among people with diabetes to be in the range 6-16 \% for type I diabetes, $0.6-26.1 \%$ for type II and $4.3-10.0 \%$ for mixed cohorts. ${ }^{3}$ A meta-analysis of 35 studies conducted in the US and Europe found the age-standardised prevalence of DMO in populations aged 20-79 years to be $6.81 \%{ }^{4}{ }^{4}$ The worldwide prevalence of DMO has been estimated to be 21 million and, as a result of the projected increase of diabetes due to ageing populations, sedentary lifestyles and dietary changes, this population is expected to rise to 100 million by $2030 .{ }^{10} \mathrm{DMO}$ generally occurs at a higher frequency in type I than type II diabetes ( $14.25 \%$ versus $5.57 \%)^{4}$ but 70 $90 \%$ of diabetes cases are type II. ${ }^{11}$ DMO prevalence also increases with duration of diabetes as shown in Figure 1: within 5 years of onset $0 \%$ and $3 \%$ of type I and type 2 diabetes, respectively, have DMO whereas after 20 years this rises to $29 \%$ and $28 \%{ }^{3}$

In developed countries, DMO is the leading cause of blindness in the working population in individuals aged 20-70 years although it occurs mostly in individuals aged 40-69 years, with similar frequency in males and females. ${ }^{2}$ It is associated with dyslipidaemia, hyperglycaemia and hypertension. ${ }^{12}$ Between $30-35 \%$ of cases spontaneously resolve within 6 months, ${ }^{13,14}$ however, the ETDRS (sponsored by the US National Eye Institute and started in 1979) (see Box for definitions of study name acronyms) has shown that without treatment, $30 \%$ of eyes with DMO 
Figure 1: Frequency of Macular Oedema by Duration of Type 2 Diabetes
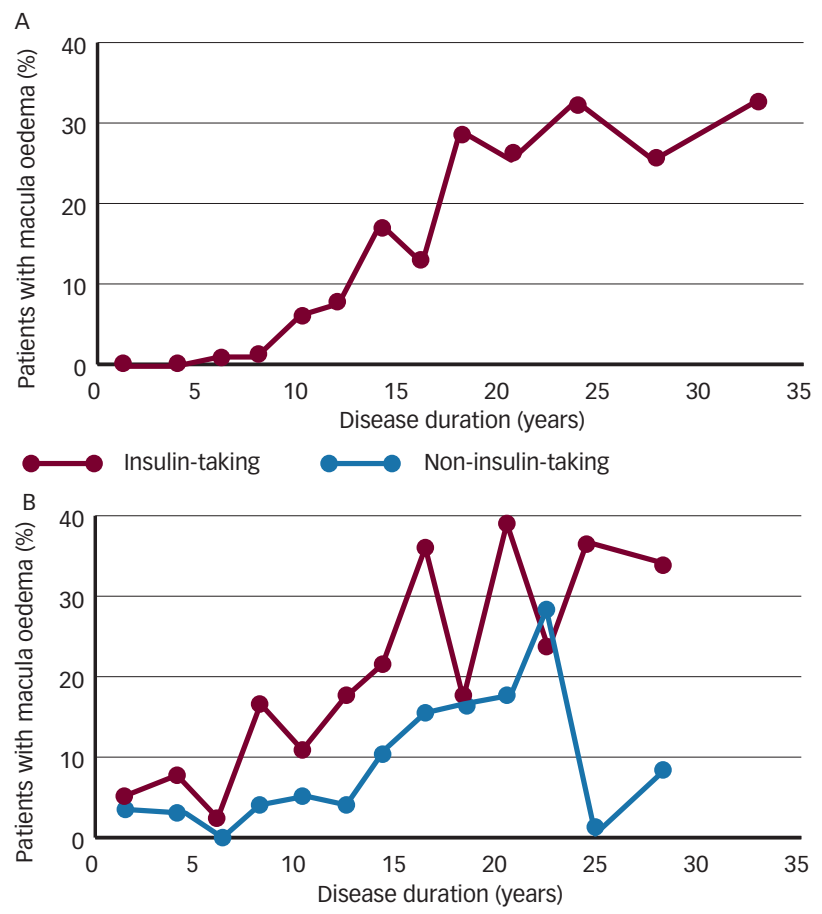

A: Insulin-treated young onset diabetes.B: Insulin-treated and non-insulin-treated older onset diabetes. Source: Klein et al. 1984. ${ }^{72}$

develop visual loss of three lines or more at 3 years. ${ }^{15}$ It has consequently been described as a costly disease that has a negative effect on patients' health-related quality of life.

\section{Pathophysiology of Diabetic Macular Oedema}

DMO is a chronic disease and a frequent complication of diabetic retinopathy. The pathophysiology of DMO is not fully understood but increases in various factors that occur in diabetes are believed to contribute to several interrelated inflammatory processes. Chronic hyperglycaemia is a feature of diabetes that results in increased levels of free radicals, advanced glycation end product (AGE) proteins, protein kinase C (PKC) and other inflammatory factors such as interleukin 6..$^{6,16}$ Hyperglycaemia also stimulates the secretion of various cytokines including insulinlike growth factor-1: the combination of these factors increases the expression of VEGF in retinal pigment epithelial cells. ${ }^{17}$ Other factors such as metalloproteases, pigment epithelium-derived factor (PEDF), angiotensin II, basic fibroblast growth factor (b-FGF) and platelet-derived growth factor (PDGF) are also believed to be involved in the pathogenesis of DMO by increasing vascular permeability and disrupting the bloodretina barrier. ${ }^{18,19}$ This leads to accumulation of excess extracellular fluid in the macula (MO) and consequent reduction in visual acuity (VA). In addition, hyperglycaemia can also directly increase PKC and angiotensin II, which stimulates endothelin synthesis leading to vasoconstriction and worsening of hypoxia. These processes are often reversible during early disease, but prolonged oedema causes irreversible vision loss.

Studies using optical coherence tomography (OCT) have revealed the structural changes and damage that occurs at the retina in patients with $\mathrm{DMO}^{20}$ There is generally an increase in central retinal thickness, which is moderately correlated with the level of VA. In addition, cystoid spaces, sponge-like retinal swelling, hyper-reflective foci, photoreceptor damage and serious retinal detachment have been observed and these effects worsen with time.
DMO occurs as focal or diffuse types according to the pattern of macular leakage observable on a fluorescein angiogram and it is important to classify which type is present prior to treatment.. ${ }^{1,22}$ In focal DMO, leakage of intravascular liquid into interstitial spaces due to vasopermeability and microaneurysms is visible as discrete points of retinal hyper-fluorescence. These points of leakage are frequently seen within circular deposits of hard exudates. Where there are multiple microaneurysms, multifocal MO may occur and this can be confused with diffuse MO. Diffuse DMO is characterised by areas of diffuse leakage that are visible as a result of any or a combination of the following factors: intra-retinal leakage from a dilated capillary bed, leakage from intra-retinal microvascular abnormalities and leakage from arterioles and venules without foci of leaking microaneurysms. ${ }^{23}$ A further subtype, cystoid diabetic $\mathrm{MO}$ (CMO), occurs as a result of widespread degradation of the inner blood retinal barrier with fluid accumulation in the outer plexiform layer. ${ }^{24}$

\section{Screening for Diabetic Retinopathy and Diabetic Macular Oedema}

In patients with diabetes, screening for DMO and determination of the risk of DMO is essential since early detection and initiation of treatment is vital to prevent irreversible vision loss. ${ }^{12}$ Initiatives for screening and ensuring rapid treatment of DMO are not given priority in many parts of the world, often because other types of preventable blindness receive more attention or are considered to be more important..$^{25}$ Some screening programmes fail to identify a large proportion of high-risk patients. ${ }^{5}$ Risk factors for DMO that should be monitored include duration of disease, severity of hyperglycaemia, hypertension and hyperlipidaemia, insulin resistance, obesity, urbanisation, access to healthcare systems, genetic susceptibility and epigenetic factors. ${ }^{25}$ The importance of controlling hyperglycaemia was demonstrated by the Diabetes control and Complications Trial (DCCT) in which maintaining glycated haemoglobin $\left(\mathrm{HbA}_{1 \mathrm{C}}\right)$ below $7 \%$ resulted in marked decreases in development and progression of diabetic retinopathy in type I diabetes. ${ }^{26}$ In addition, some racial groups such as South Asian, African, Latin American and some indigenous tribal groups show a higher prevalence of DMO compared with white populations, making screening efforts more urgent. ${ }^{25}$

Success of screening has been demonstrated in the US where rates of non-proliferative diabetic retinopathy are declining as a result of these programmes. ${ }^{25}$ In the UK, the NHS Diabetic Eye Screening Programme provides annual digital fundus photography for all patients with diabetes over 12 years of age. ${ }^{27}$ This programme aims to detect all forms of diabetic retinopathy and maculopathy and has achieved a reported take-up of $79 \%$. In cases where disease is detected, the patient is referred to a specialist eye unit for further assessment and treatment within a pre-specified timeframe. Screening for diabetic retinopathy and DMO is becoming more widespread and accessible with the use of teleretinal scanning. Several studies have found that using cameras remote from treatment centres is an efficient and reliable means of screening diabetic populations, particularly those in remote locations. ${ }^{28,29}$

\section{Photocoagulation as a Treatment for Diabetic Macular Oedema}

Laser photocoagulation been used for many years in the treatment of $\mathrm{DMO}$ and has proved effective in stabilising visual function reducing the rate of vision loss. The ETDRS group showed that laser treatment halved the 3-year risk of moderate visual loss (a decrease in VA score of 15 or more letters or moving from $20 / 20$ to $20 / 40$ in the optotypes scale) a reduction from $24 \%$ in untreated eyes to $12 \%$ in treated eyes. ${ }^{15}$ 
Table 1: Major Clinical Studies and Quality of Evidence on Ranibizumab Treatment of Diabetic Macular Oedema

\begin{tabular}{|c|c|c|}
\hline \multicolumn{2}{|c|}{$\begin{array}{l}\text { Study Name/ Study Design } \\
\text { Reference }\end{array}$} & $\begin{array}{l}\text { Number of Patients } \\
\text { and Treatments }\end{array}$ \\
\hline \multicolumn{3}{|c|}{ Ranibizumab studies } \\
\hline RESOLVE ${ }^{54}$ & $\begin{array}{l}\text { Randomised, } \\
\text { double-masked, } \\
\text { multicentre, } \\
\text { laser-controlled } \\
\text { phase III study }\end{array}$ & $\begin{array}{l}\text { Pts randomised to } \\
\text { ranibizumab + sham laser } \\
(n=116), \text { ranibizumab + } \\
\text { laser }(n=118) \text { or sham } \\
\text { injections + laser }(n=111)\end{array}$ \\
\hline RESTORE ${ }^{55}$ & $\begin{array}{l}\text { Core 12-month } \\
\text { double-masked, } \\
\text { multicentre, } \\
\text { laser-controlled } \\
\text { phase III study }\end{array}$ & $\begin{array}{l}\text { Pts randomised to } \\
\text { ranibizumab + sham laser } \\
(n=116) \text {, ranibizumab } \\
+ \text { laser }(n=118) \text { or sham } \\
\text { injections + laser }(n=111)\end{array}$ \\
\hline
\end{tabular}

$\begin{array}{ll}\text { RESTORE } & \text { Extension of } \\ \text { 2-year } & \text { RESTORE study } \\ \text { data }^{53} & \text { Long-term safety } \\ & \text { and efficacy data }\end{array}$

240 pts (79 \%) entered the extension study during months 12-36; all pts in the ranibizumab and ranibizumab + laser groups were eligible to receive ranibizumab PRN
REVEAL ${ }^{69} \quad$ Multicentre
RESTORE $^{59}$ COSteffectiveness analysis based on 1-year data randomised phase III trial

Outcomes measured in QALYS were simulated for a 15-year time horizon based on 12 month follow up from RESTORE and published long-term data $\mathrm{n}=390$ ranibizumab $0.5 \mathrm{mg}$, ranbizumab $0.5 \mathrm{mg}+$ laser or laser alone in Asian pts with $\mathrm{DMO}$

\begin{tabular}{ll}
\hline DRCRNet & Multicentre, \\
2-year & randomised \\
data $^{52}$ & phase III trial - \\
& expanded \\
& 2-year data
\end{tabular}

DRCRNet Multicentre, 3-year data ${ }^{56}$ randomised data $^{56} \quad$ trial
Main Endpoints/Findings

After 12 months, significantly more pts had BCVA letter score $\geq 15$ and BCVA letter score level $>73$ (20/40) with ranibizumab ( $22.6 \%$ and $53 \%$, respectively) and ranibizumab + laser (22.9\% and $44.9 \%$ ) vs laser (8.2\% and $23.6 \%$ ) Mean CRT was significantly reduced with ranibizumab $(-118.7 \mu \mathrm{m})$ and ranibizumab + laser $(-128.3 \mu \mathrm{m})$ vs laser $(-61.3 \mu \mathrm{m}$; both $\mathrm{p}<0.001)$ At 12-months, the mean composite NEI VFQ-25 score improved by 5.0 ( $p=0.01$ vs laser) and $5.4(p=0.004)$ from baseline in the ranibizumab and ranibizumab + laser groups vs 0.6 for laser. In the ranibizumab and ranibizumab + laser groups distance activities score improved by 5.3 ( $p=0.04$ vs laser) and 5.6 ( $p=0.03$ vs laser) compared with 0.4 for laser. Pts with better baseline visual acuity or lower central retinal thickness had greater improvements with ranibizumab vs laser in composite and some subscales scores

Mean BCVA change of +7.9 for ranibizumab and +6.7 for ranibizumab + laser) letters at 24 months. The mean CRT was ranibizumab: $-140.6 \mu \mathrm{m}$ and ranibizumab + laser: $-133.0 \mu \mathrm{m}$. An average of 3.8 ranibizumab injections over the three core treatment groups was sufficient to maintain (or improve BCVA), and CRT outcomes in the extension study. AEs were consistent with the published safety profile

Ranibizumab alone produced a 0.17 QALY gain at an incremental cost of $£ 4,191$ relative to laser monotherapy, yielding an ICER $£ 24,028$. Probabilistic sensitivity analysis showed a $64 \%$ probability of being cost-effective at a threshold of $£ 30,000$ per QALY At 1 year, ranibizumab alone or + laser produced a significant improvement in mean BCVA vs laser alone $(p<0.0001)$ and mean visual gains were 6.6 and 6.4 letters, but 1.8 letters for laser alone. Mean CRT at 12 months for ranibizumab alone or with laser were significantly lower vs laser-alone $(p=0.001)$

After 2 years the mean change in BCVA letter score from baseline was 3.7 letters greater for ranibizumab + prompt laser vs 5.8 letters for ranibizumab + deferred laser group and 1.5 letters worse for triamcinolone plus prompt laser. The median number of injections for each were 2 and 3 , respectively (potential maximum of 13). Proportion of eyes with CRT $\geq 250 \mu \mathrm{m}$ were: $59 \%$ for sham + prompt laser, $43 \%$ for ranibizumab + prompt laser $42 \%$ for ranibizumab + deferred laser, $52 \%$ for triamcinolone + prompt laser. No AEs caused by study treatment were reported Mean change in visual acuity letter score at 3 years was 2.9 letters greater $(p=0.02)$ in the deferral group compared with the prompt laser treatment group and $42 \%$ and $56 \%$ of eyes with $a \geq 10$ letter gain was $(p=0.02) .36 \%$ of eyes in both groups had central subfield thickness $\geq 250 \mu \mathrm{m}(p=0.90)$

RIDE/RISE studies $^{57}$ Parallel, phase III, $\quad 377$ pts and 382 pts randomised multicentre, double- (127 to sham, 125 to $0.3 \mathrm{mg}$, masked, sham 125 to $0.5 \mathrm{mg}$ ) injection-controlled, randomised study 3-year follow-up of participants in study groups treated with prompt or deferred laser and ranibizumab $0.5 \mathrm{mg} \mathrm{n}=361$
At 24 months $12.3 \%$ and $18.1 \%$ of sham pts gained $\geq 15$ letters: vs $33.6 \%$ and $44.8 \%$ of $0.3 \mathrm{mg}$ ranibizumab pts ( $p<0.0001$ for both) and $45.7 \%$ of $0.5 \mathrm{mg}$ ranibizumab pts $(p<0.0001$ and $p<0.001)$. Significantly less macular oedema were noted in OCT, and retinopathy was less likely to worsen with ranibizumab
Limitations/Quality of Evidence

High-quality evidence After 12 months no differences were detected between the ranibizumab and ranibizumab + laser arms

High-quality evidence The pt-reported outcomes supports benefits from ranibizumab or ranibizumab + laser, for pts with DMO

High-quality evidence Ranibizumab was associated with VF improvements in treatment groups over 2 years. The outcomes of the extension study further support the long-term safety and efficacy of ranibizumab in DMO Ranibizumab monotherapy appears to be cost-effective relative to laser monotherapy; however the cost-effectiveness of combination therapy is less certain The REVEAL study results are consistent with the RESTORE trial; ranibizumab monotherapy can result in rapid and significant improvement in vision and reduction in CRT vs laser alone High-quality evidence. Large controlled study. Ranibizumab should be considered for pts with $\mathrm{DMO}$ and characteristics similar to those of the cohort in this clinical trial

Results suggest laser treatment at the initiation of ranibizumab is no better for vision outcomes, and possibly worse than deferring laser treatment for $\geq 24$ weeks in DMO involving the fovea and vision impairment High-quality evidence Ranibizumab rapidly and sustainably improved vision loss, and improved macular oedema in pts with $\mathrm{DMO}$, with low rates of ocular and non-ocular harm 


\section{Diabetic Macular Oedema}

Table 1: Continued

\begin{tabular}{|c|c|c|c|c|}
\hline $\begin{array}{l}\text { Study Name/ } \\
\text { Reference }\end{array}$ & Study Design & $\begin{array}{l}\text { Number of Patients } \\
\text { and Treatments }\end{array}$ & Main Endpoints/Findings & $\begin{array}{l}\text { Limitations/Quality } \\
\text { of Evidence }\end{array}$ \\
\hline \multicolumn{5}{|c|}{ Ranibizumab studies } \\
\hline $\begin{array}{l}\text { RIDE/RISE } \\
\text { analysis }{ }^{70}\end{array}$ & $\begin{array}{l}\text { Analysis of joint } \\
\text { study data }\end{array}$ & $\begin{array}{l}\mathrm{n}=605 \text { study participants with } \\
\text { NEI VFQ- } 25 \text { scores at both } \\
\text { baseline and month } 24 \\
\text { Analysed predictors of } \\
\text { improvement in self-reported } \\
\text { visual function }\end{array}$ & $\begin{array}{l}\text { Predictors were: treatment with ranibizumab vs sham } \\
(p=0.03) \text {, higher baseline contrast sensitivity in untreated } \\
\text { eye }(p<0.001) \text {, lower baseline systolic blood pressure } \\
(p<0.03) \text { and lower baseline NEI-VFQ-25 score }(p<0.0001)\end{array}$ & $\begin{array}{l}\text { No pt-reported visual } \\
\text { functions precluded ranibizumab } \\
\text { treatment for DMO. Baseline } \\
\text { visual acuity in the treated eye } \\
\text { did not necessarily predict } \\
\text { improvement in visual function }\end{array}$ \\
\hline RETAIN $^{71}$ & $\begin{array}{l}\text { Randomised, } \\
\text { phase IIIb single- } \\
\text { masked, multi- } \\
\text { centre, controlled }\end{array}$ & $\begin{array}{l}\mathrm{n}=374 \text { 2-year randomised, } \\
\text { single-masked, multicentre, } \\
\text { controlled phase IIIb trial } \\
\text { conducted in Europe }\end{array}$ & $\begin{array}{l}\text { Study assesses the efficacy and safety of in ranibizumab } \\
\text { in two 'treat and extend' treatment algorithms: } 0.5 \mathrm{mg} \\
\text { ranibizumab vs } 0.5 \mathrm{mg} \text { ranibizumab as needed in pts with } \\
\text { DMO. Primary endpoint: change in BCVA over } 12 \text { months }\end{array}$ & First results reported Nov 2013 \\
\hline
\end{tabular}

$A E=$ adverse events; $B C V A=$ best-corrected visual acuity; $C R T=$ central retinal thickness; $D M O=$ diabetic macular oedema; ICER = incremental cost-effectiveness ratio; NEI VFQ-25 =National Eye Institute Visual Functioning Questionnaire-25; OCT = optical coherence tomography; PRN = pro re nata; $p t=p a t i e n t ; ~ Q A L Y=$ quality-adjusted life-year; $V F=$ visual functioning.

Laser treatment of DMO is divided into focal and grid types. ${ }^{13,30}$ Focal laser treatment is suitable for specific points of leakage such as microaneurysms or intra-retinal microvascular abnormalities that are between 500 and $3,000 \mu \mathrm{m}$ from the centre of the macula. The intensity of laser treatment depends on the size of the lesion treated. The laser exposure of 0.05-0.1 second duration results in burns of 50-100 $\mu \mathrm{m}$ of moderate intensity. Effective treatment is indicated by the appearance of whitening or darkening of focal lesions. Grid laser treatment covers a wider area for a duration of $0.05-0.5$ second with a spot size of 50-200 $\mu \mathrm{m}$, to achieve mild retinal pigment epithelium whitening. The power is adjusted to prevent the burns from spreading to more than $200 \mu \mathrm{m}$ in diameter. The size of the grid can be up to two disc diameters $(3,000 \mu \mathrm{m})$ from the centre of the macula.

It is not fully understood how laser photocoagulation improves the symptoms of DMO and it is not clear what effects this treatment has on macular VEGF levels. It has been proposed that oxygen-consuming peripheral-retina photoreceptors are destroyed by the laser resulting in greater oxygen in the macular area photoreceptors. An alternative explanation is that oxygen diffusion can occur through the laser scars to the inner retina resulting in autoregulatory vasoconstriction that may decrease fluid leakage and swelling thus improving DMO. It has also been suggested that biological activities are stimulated in the areas around the burned region that did not receive a lethal dose of laser radiation. ${ }^{31}$

Despite some efficacy in DMO, laser photocoagulation can cause scarring and progressive atrophy in surrounding tissue leading to further oedema and vision loss at a later stage. In such areas the possibility of retreatment is limited. Since 1990, micropulsed laser treatment has emerged. This uses a longer wavelength $(810 \mathrm{~nm})$ and longer off-times during treatment resulting in less heat generation at the retina and less damage to surrounding tissues. Subthreshold photocoagulation has been developed using this technique that causes little or no damage on the surrounding retina. ${ }^{32,33}$ Laser surgery has been the 'gold standard' treatment for DMO and is widely used. In recent years, however, there has been a move away from laser treatments towards the use of medications although combination treatments of both laser photocoagulation and medications have been shown to be effective in various clinical trials. ${ }^{34}$

\section{Surgical Approaches for Diabetic Macular Oedema}

Vitrectomy involves the surgical removal of all or part of the vitreous humour, which may have become fogged with blood or exudate (including
AGE proteins), and is often carried out with peeling of the internal limiting membrane (ILM). ${ }^{35-37}$ Studies show that vitrectomy is useful only in cases of vitreomacular traction, ${ }^{38}$ but results have been variable and inconclusive. A study on 40 eyes showed that vitrectomy with or without ILM did not improve the eyesight in patients with type $\|$ diabetes and DMO and no vitreoretinal traction. Another study conducted by the DRCRNet on 87 eyes with DMO showed that 6 months after vitrectomy $68 \%$ had at least a $50 \%$ reduction in central field thickness. ${ }^{39}$ VA improved by $\geq 10$ letters in $38 \%$ and deteriorated by $\geq 10$ letters in $22 \%$. It was concluded that $28-49 \%$ of eyes with characteristics similar to those included in this study are likely to have improvement of VA, whereas $13-31 \%$ are likely to have worsening. Some animal model work has indicated that there may be greater clearance of exogenously applied VEGF after vitrectomy ${ }^{40}$ but this needs elucidation as a mechanism in laser treatment of DMO.

The value of vitrectomy with or without ILM peeling was further investigated in a Cochrane analysis of four clinical studies conducted in Europe and Hong Kong $(n=47,80,49$ and 141$) .{ }^{41}$ This analysis found there was no difference in acuity of distance vision at 6 or 12 months after surgery between patients receiving or not receiving ILM peeling.

Various complications may occur following vitrectomy including cataract, retinal detachment, epiretinal membrane, glaucoma and vitreous haemorrhage. ${ }^{42}$ The use of vitrectomy therefore tends to be limited to tractional or taut DMO for which laser treatment is inappropriate.

\section{Diabetic Macular Oedema Steroid Treatments}

Steroid treatments have been successfully used intravitreally, in the treatment of DMO for many years due to their anti-angiogenic, antioedematous, anti-inflammatory, anti-apoptotic and anti-proliferative effects. ${ }^{7}$ Steroids may reduce the concentration of inflammatory cytokines and growth factors, and increase vascular permeability. Systemic or topical application often fails to achieve intraocular therapeutic concentrations so doses need to be high but this can result in severe systemic side effects. Intravitreal injections can be effective but can cause cataracts and elevated IOP. Intravitreal steroid implants, however, can be used as an alternative to frequent injections. ${ }^{7}$

The evidence supporting steroid use in $\mathrm{DMO}$, however, is variable. Example data come from a US study of 840 eyes that were treated with intravitreal triamcinolone $1 \mathrm{mg}$ or $4 \mathrm{mg}$ or focal/grid photocoagulation. ${ }^{43}$ Three years after treatment, the change in VA letter score from baseline was +5 in the laser group and 0 in each triamcinolone group. The 
cumulative probabilities of cataract surgery in these groups were $46 \%$ and $83 \%$ and $31 \%$, respectively. These results indicated no long-term benefit of triamcinolone treatment over photocoagulation.

Steroid treatments for DMO have been more successful when administered as intravitreal implants. Several small European studies have reported favourable findings of dexamethasone implants in terms of improved eyesight over 6 months after treatment. Improvements were seen in ETDRS vales ( 18.80 at baseline changed to 26.15 after 1 month; $p=0.04$ ) and the central macular thickness (518.80 $\mu \mathrm{m}$ at baseline to $412.75 \mu \mathrm{m}$, at day 3 and 292.0 after 1 month; $p<0.0001){ }^{44}$ These implants have also been shown to provide significant improvements in best-corrected VA (BCVA) and central macular thickness in patients with persistent or refractory DMO 1 month after injection. ${ }^{45}$ Another steroid used in DMO treatment is fluocinolone acetonide given as intravitreal injections or implants. ${ }^{46}$ Fluocinolone acetonide implants have shown efficacy significant improvements in VA as shown in the FAME study $(n=953){ }_{1}{ }^{77}$ but have been associated with cataract formation and elevated intraocular pressure. The fluocinolone acetonide insert has been approved for use in Europe ${ }^{48}$ but it is generally reserved for cases in which first-line therapy has failed.

The exact role of steroids for diabetic retinopathy and $\mathrm{MO}$ remains to be fully elucidated: their reported efficacy is variable but they continue to have a valuable role in treatment. Steroids are often used in conjunction with laser photocoagulation treatment and have been reported to prevent further vision loss. ${ }^{49}$ In addition, steroid treatments have been used as adjunct or comparator treatments to anti-VEGF treatments in multiple clinical trials ${ }^{50,51}$ and in some reports the combination has an improved efficacy over the anti-VEGF drug used alone.

\section{Anti-vascular Endothelial Growth Factor Treatments in Diabetic Macular Oedema}

There are several anti-VEGF agents that have been used in the treatment of DMO but ranibizumab (Lucentis ${ }^{\circledR}$, Novartis) is the only one that has been approved by the US Food and Drug administration (FDA) and European Medicines Association (EMA) for use in this indication. Ranibizumab is approved as a $0.3 \mathrm{mg}$ intravitreal monthly dose, but in the EU it is approved as a $0.5 \mathrm{mg}$ intravitreal monthly dose. The use of this drug in DMO is supported by an extensive series of clinical trials that have included over 2,000 patients and these are reviewed in Table $1-$ extensions of these studies are ongoing.

Several of the major studies (RESOLVE, RESTORE, REVEAL, DRCRNet ${ }^{52-56}$ ) compared ranibizumab with laser treatment or included arms in which patients were treated with both ranibizumab and laser. In each case, ranibizumab improved VA (BCVA letter score) and in some studies decreased central retinal thickness to a greater extent than laser treatment alone. In the DRCRNet study, both prompt or deferred laser treatment in combination with ranibizumab treatment, provided greater mean changes in VA at 2 years compared with prompt laser treatment alone or prompt laser treatment and triamcinolone (see Figures 2 and 3). ${ }^{52}$ The mean change in VA letter score from baseline was 3.7 letters greater in the ranibizumab with prompt laser group, 5.8 letters greater in the ranibizumab with deferred laser treatment and 1.5 letters worse in the triamcinolone plus prompt laser group. There was also a greater reduction in central subfield retinal thickness (measured by OCT) after 2 years, the percentages of eyes with central subfield thickness $\geq 250 \mu \mathrm{m}$ were: $43 \%$ in the ranibizumab + prompt laser group, $42 \%$ in the ranibizumab + deferred laser group, $52 \%$ in the triamcinolone + prompt laser group and $59 \%$ in the prompt laser alone group.

\section{Figure 2: Mean Change in Visual Acuity in a Cohort that Completed 2-Year Visit in a Diabetic Retinopathy Clinical Research Network Study}
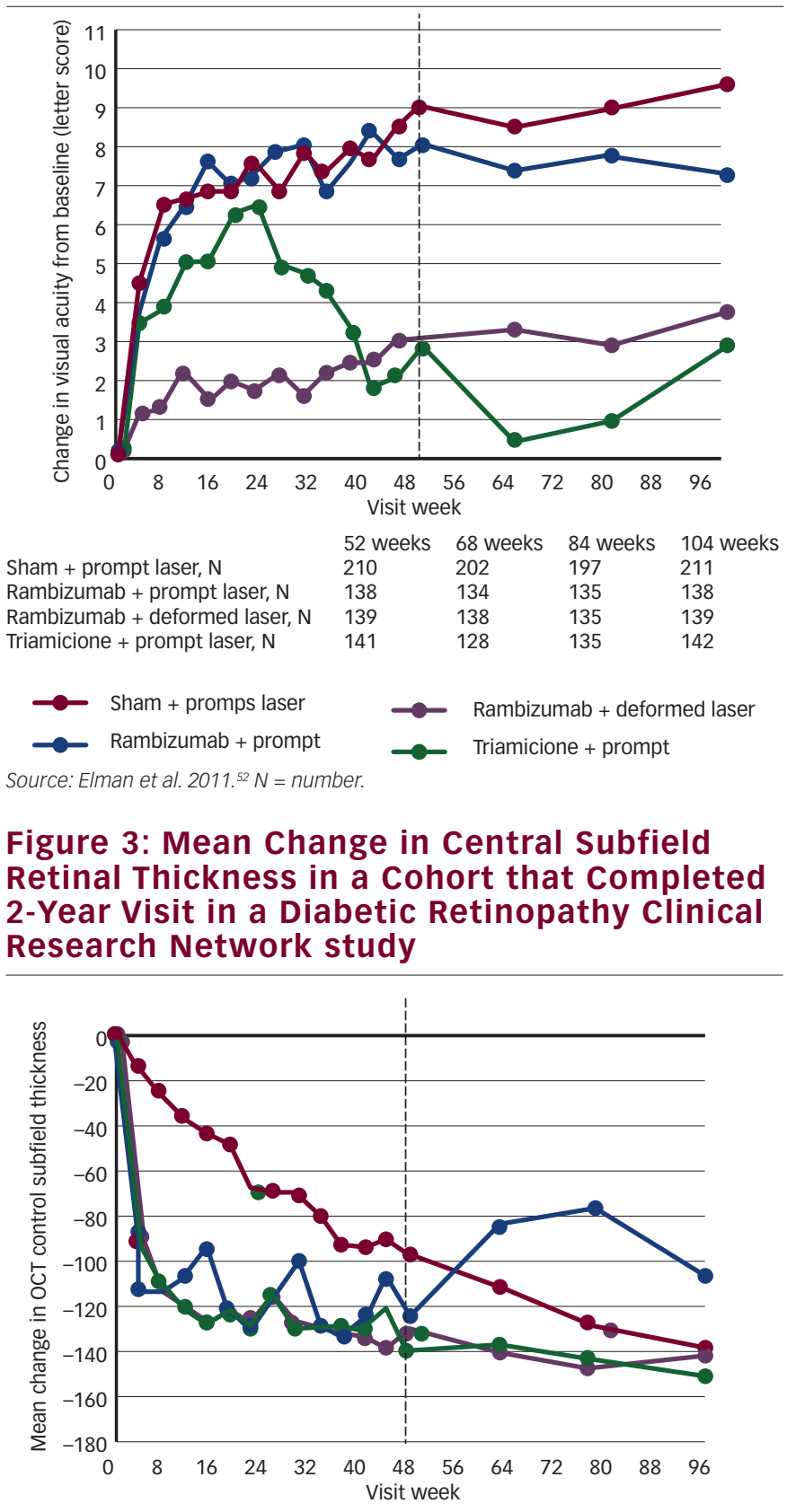

Sham + promps laser, $\mathrm{N}$

Rambizumab + prompt laser, $\mathrm{N}$ Rambizumab + deformed laser, $\mathrm{N}$ Triamicione + prompt laser, N

$\begin{array}{llll}52 \text { weeks } & 68 \text { weeks } & 84 \text { weeks } & 104 \text { weeks } \\ 207 & 195 & 178 & 203 \\ 198 & 135 & 134 & 131 \\ 195 & 133 & 132 & 135 \\ 199 & 123 & 124 & 132\end{array}$

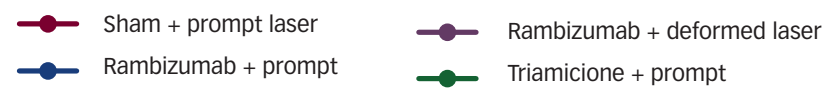

Source: Elman et al. $2011 .{ }^{52} \mathrm{~N}=$ number; OCT = optical coherence tomography.

In the RIDE and RISE studies, after 24 months , $18.1 \%$ of sham-treated patients gained $\geq 15$ letters versus $44.8 \%$ of $0.3 \mathrm{mg}(\mathrm{p}<0.0001)$ and $39.2 \%$ of $0.5 \mathrm{mg}$ ranibizumab-treated patients $(p<0.001) .^{57}$ Ranibizumab-treated patients also showed significant improvements in $\mathrm{MO}$ (measured by OCT) and needed significantly fewer macular laser procedures. More recently, 3-year long-term results from the DRCRNet study and 2-year results from the RESTORE study showed long-term maintenance of visual improvements. ${ }^{56,58}$ The 3-year data show that long-term ranibizumab is 


\section{Table 2: Major Clinical Studies and Quality of Evidence on Bevacizumab, Aflibercept and Pegaptanib in the Treatment of Diabetic Macular Oedema}

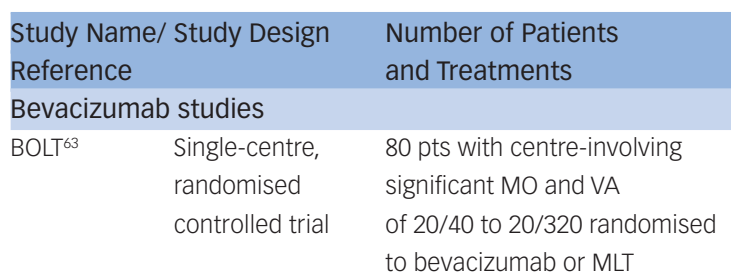

PACORES ${ }^{61} \quad$ Retrospective, Primary intravitreal bevacizumab interventional, alone (Group A), 120 eyes of 94 pts comparative, multicentre study

DRCRNet ${ }^{62}$ Randomised phase II clinical trial
Main Endpoints/Findings

Mean (SD) BCVA was 64.4 (13.3) bevacizumab and 54.8 (12.6) (20/80) for MLT ( $p=0.005)$. Bevacizumab treated pts gained a median 9 letters vs 2.5 letters for MLT ( $p=0.005)$. Mean reduction in CRT: $146 \mu \mathrm{m}$ for bevacizumab vs $118 \mu \mathrm{m}$ for MLT with GLP therapy (Group B), and 157 eyes of 104 pts treated with IVB plus GLP (Group C)

Group A laser at baseline $(\mathrm{n}=19)$, Group B bevacizumab $1.25 \mathrm{mg}$ at baseline and 6 weeks ( $n=22)$, Group $\mathrm{C}$ bevacizumab at baseline and 6 weeks ( $n=24)$, Group D bevacizumab $1.25 \mathrm{mg}$ at baseline and sham injection at 6 weeks $(\mathrm{n}=22)$ or Group E bevacizumab $1.25 \mathrm{mg}$ at baseline and 6 weeks with laser at 3 weeks $(n=22)$
Improvement BCVA after 24 months $(p<0.0001)$ than Group $B(p=0.013)$. Decrease in central macular thickness in all groups after 24 months $(p<0.0001)$. Higher central macular thickness decrease in Group $A$ than in Groups B and C $(p<0.001)$

Group A vs Groups B and C had a greater reduction in CST at 3 weeks and about 1 line better median VA over 12 weeks. No marked differences between groups B and C in CST reduction or VA improvement
Limitations/Quality of Evidence

Medium-sized study. The results

support longer-term use of intravitreal bevacizumab for persistent centre-involving CSMO. BCVA and central macular thickness improvements seen with bevacizumab maintained over the second year with a mean of 4 injections Results support primary IVB with or without GLP for treatment of diffuse DMO. Primary IVB without GLP appeared to be superior to GLP alone for stability or in BCVA in pts with diffuse DMO Small trial (phase II) Intravitreal bevacizumab was shown to reduce DMO in some eyes. Study was not designed to determine whether treatment is beneficial

\section{Aflibercept studies}

$\begin{array}{lll}\text { DA VINCI }^{65} & \text { Randomised, } & 221 \text { pts in } 5 \text { randomised groups } \\ \text { double-masked, } & \text { 1:VEGF aflibercept } 0.5 \text { mg every } \\ \text { multicentre, } & 4 \text { weeks }(0.5 q 4) ; 2: 2 \text { mg every } \\ \text { phase II clinical } & 4 \text { weeks (2q4); 3: } 2 \text { mg every } \\ \text { trial 52 weeks } & 8 \text { weeks after } 3 \text { initial monthly } \\ & \text { doses (2q8); } 4: 2 \text { mg dosing as } \\ & \text { needed after } 3 \text { initial monthly } \\ & \text { doses (2PRN); } 5 . \text { macular laser } \\ & \text { photocoagulation }\end{array}$

\begin{tabular}{|c|c|c|}
\hline $\mathrm{VIVID}^{65}$ & $\begin{array}{l}\text { Double-blind } \\
\text { phase III } \\
\text { masked, } \\
\text { randomised, } \\
\text { active-controlled } \\
\text { study }\end{array}$ & $\begin{array}{l}\mathrm{n}=404 \text { pts with DMO treatment } \\
\text { arms: aflibercept } 2 \text { mg monthly, } \\
\text { aflibercept } 2 \text { mg every } 2 \text { months } \\
\text { after an initial } 5 \text { monthly } \\
\text { months injections or laser } \\
\text { photocoagulation. Conducted } \\
\text { in Asia, Europe and and Australia }\end{array}$ \\
\hline VISTA $^{67}$ & $\begin{array}{l}\text { Double-blind } \\
\text { phase III masked, } \\
\text { randomised, } \\
\text { active-controlled } \\
\text { study }\end{array}$ & $\begin{array}{l}\mathrm{n}=466 \text { pts with DMO treatment } \\
\text { arms: aflibercept } 2 \text { mg monthly, } \\
\text { aflibercept } 2 \text { mg every } 2 \text { months } \\
\text { after an initial } 5 \text { monthly injections, } \\
\text { or laser photocoagulation. } \\
\text { Conducted in US }\end{array}$ \\
\hline
\end{tabular}

Mean improvements in BCVA with VEGF aflibercept were 11.0, 13.1, 9.7 and 12.0 letters for $0.5 q 4,2 q 4$, 2q8 and 2PRN regimens versus -1.3 letters for laser treatment ( $x \leq 0.0001 \mathrm{vs}$ laser). Mean reductions in CRT for VEGF Trap-Eye were -165.4 $\mu \mathrm{m},-227.4 \mu \mathrm{m}$, $-187.8 \mu \mathrm{m}$ and $-180.3 \mu \mathrm{m}$ vs $-58.4 \mu \mathrm{m}$ for laser $(p<0.0001$ vs laser). Ocular AEs: conjunctival haemorrhage, eye pain, ocular hyperaemia and increased IOP systemic AEs: hypertension, nausea and congestive heart failure

Preliminary results show that aflibercept $2 \mathrm{mg}$ monthly produced a mean change from baseline in BCVA of 10.5 letters ( $p<0.0001$ vs laser) aflibercept $2 \mathrm{mg}$ every other month (after 5 initial monthly injections) showed a change of 10.7 letters $(p<0.0001$ vs laser), pts receiving laser had a mean change from baseline in BCVA of 1.2 letters

Preliminary results show aflibercercept $2 \mathrm{mg}$ monthly change from baseline in BCVA of 12.5 letters ( $p<0.0001$ vs laser) and aflibercept 2 mg every other month (after 5 initial monthly injections) had a mean change from baseline in BCVA of 10.7 letters $(p<0.0001$ vs laser), pts receiving laser had a mean change in BCVA of 0.2 letters

\section{Pegaptanib study}

Macugen Randomised, $\quad n=172$ pts with DMO involving the More pts receiving $0.3 \mathrm{mg}$ gained VAs of $\geq 10$ letters Diabetic double-masked, centre of the macula. Intravitreous (34\% vs $10 \%$; $p=0.003$ ) and $\geq 15$ letters ( $18 \%$ vs $7 \%$; Retinopathy multicentre, Study dose-ranging, Group ${ }^{68} \quad$ controlled trial pegaptanib (0.3 mg, $1 \mathrm{mg}, 3 \mathrm{mg}) \quad \mathrm{p}=0.12)$. Mean CRT decreased by $68 \mu \mathrm{m}$ with $0.3 \mathrm{mg}$

Phase II trial in a moderately large pt population
High-quality evidence. Significant improvements in BCVA were seen at week 24 and were maintained or improved at week 52 in all VEGF Trap-Eye-treated pts

Study ongoing (due to complete 2013). At 1 year, mean change in BCVA: 10.5, 10.7 and 1.2 letters in the 3 groups $(p<0.0001$ for aflibercept vs laser). Most frequent ocular AEs were conjunctival haemorrhage, eye pain and vitreous floaters Study ongoing (due to complete November 2014)

$\overline{A E}=$ adverse events; BCVA = best-corrected visual acuity; $C R T=$ central retinal thickness; CST = central subfield thickness; CSMO = clinically significant macular oedema; $D M O=$ diabetic macular oedema; $G L P=$ grid laser photocoagulation; IOP = intraocular pressure; IVB = intravitreal bevacizumab; $M L T=$ macular laser therapy; $P R N=$ pro re nata; $p t=$ patient; $S D=$ standard deviation; $V E G F=$ vascular endothelial growth factor. 
well tolerated with no retinal toxicity up to 3 years. Longer term follow-up in this trial is in progress.

The RESTORE study has also shown significant improvements in quality of life with ranibizumab compared with laser alone and improvements in National Eye Institute Visual Functioning Questionnaire-25 (NEI VFQ-25) composite score. Analysis of the RESTORE trial 12-month data suggests that ranibizumab is cost-effective relative to laser treatment but the economics of combined therapy is less certain. 59

The ongoing RETAIN study is comparing two 'treat and extend' (TE) regimens of ranibizumab $0.5 \mathrm{mg}$ (with or without laser photocoagulation) and a further group receiving the drug as needed (pro re nata [PRN]) in the treatment of 372 patients with DMO. ${ }^{60}$ The advantage of TE regimens is that patients can be treated at any of their follow-up visits but the interval can be increased until the next visit. With PRN dosing, patients can be treated according to individual disease activity, but with fixed monthly monitoring schedules. Interim results show no differences in outcomes between PRN and TE groups. There was a small increase in the number of injections and significantly fewer visits in the TE groups.

In these trials, ranibizumab showed a favourable safety profile and patient tolerability in the treatment of DMO and that adverse events were mainly confined to ocular symptoms. In the DRCRNet study, retinal detachment was reported in $1 \%$ of patients compared with $<1 \%$ in those treated with laser alone and ocular vascular events were reported in $1 \%$ in both these groups compared with $2 \%$ for laser with triamcinolone. ${ }^{52}$ Endophthalmitis is also less common adverse event associated with ranibizumab although this was absent in the RESTORE trial5 ${ }^{54,58}$ but reported in $1 \%$ of ranibizumab-treated patients in the DRCRNet trials2 and in $1.6 \%$ in the RIDE and RISE trials. ${ }^{57}$ The DRCRNet study also showed that ranibizumab does not increase the incidence of cardiovascular events compared with sham treatment or triamcinolone (non-fatal myocardial infarction, non-fatal cerebrovascular accident or vascular death). ${ }^{52}$ Other systemic effects were either not reported ranibizumab or no more frequent than those occurring in sham- or laser-treated patients. ${ }^{52,54}$

Bevacizumab (Avastin ${ }^{\circledR}$, Genentech) has also been used in DMO treatment but is not approved for this indication and treatment is therefore off label. Various medium and smaller studies have shown improvement in VA and retinal thickness compared with laser treatment alone (see Table 2). ${ }^{61-63}$ The data supporting bevacizumab in DMO, however, are generally of less high quality than that supporting ranibizumab. Bevacizumab is associated with various safety concerns including necrotising fasciitis, haemorrhage, gut perforation and wound-healing problems and serious systemic side effects. ${ }^{64}$ Longterm safety and tolerability data are needed to support its use in DMO.

Aflibercept (Eylea ${ }^{\circledR}$, Bayer) has also been used for DMO treatment, but it is also not yet approved for this indication (see Table 2). Different monthly dosing schedules of $0.5 \mathrm{mg}$ and $2.0 \mathrm{mg}$ aflibercept showed notable efficacy compared with laser treatment alone in the DA VINCI study. ${ }^{.5} \mathrm{AES}$ included: conjunctival haemorrhage, eye pain, ocular hyperaemia and increased IOP systemic AEs: hypertension, nausea and congestive heart failure. The ongoing VIVID and VISTA studies comparing aflibercept with laser treatment in DMO have shown marked improvement in BCVA for aflibercept after 1 year of treatment. ${ }^{66,67}$ Long-term efficacy and safety data from these trials will provide better evidence supporting the use of this treatment in DMO.

Pegaptanib sodium (Macugen ${ }^{\circledR}$, Eyetech Pharmaceuticals), a treatment approved for neovascular (wet) age-related macular degeneration, is not approved for DMO but has recently been studied in a phase II trial for this indication. ${ }^{68}$ Patients who were treated for 36 weeks with 0.3 , 1 and 3 mg pegaptanib $(n=172)$ showed significant improvements in VA and significant decreases in mean central retinal thickness compared with sham injections. Laser photocoagulation was required in $25 \%$ of the $0.3 \mathrm{mg}$ group compared with $48 \%$ of the sham injection group $(p=0.04)$ and the injections were well tolerated.

\section{Conclusion}

With the substantial rise in both type I and type || diabetes in most populations, the incidence and prevalence of DMO is increasing but more effective therapies to tackle it are evolving. The established laser photocoagulation approach is being replaced or augmented with newer treatments. Steroid treatments can be given as implants and pulsed or sub-threshold laser treatments are less damaging to retinal tissues. The principal change in DMO therapy, however, is the use of anti-VEGF treatments, in particular, ranibizumab. An extensive body of clinical trial evidence now supports ranibizumab; follow-up results now extend to 3-years and show sustained efficacy and tolerability. Experience with this drug is also increasing with clinical use. Other anti-VEGF agents, bevacizumab, aflibercept and pegaptanib have also shown efficacy in DMO, but the data supporting these are, as yet, limited.

DMO is an urgent problem and a substantial cause of vision loss worldwide. The anti-VEGF treatments, in particular, ranibizumab are increasingly important as a means of controlling it and are more effective than other medications currently available. Ranibizumab has been shown to be cost-effective and improves quality of life relative to laser treatment: it is therefore likely to have a central role in DMO therapy for the foreseeable future.
1. Chen $\mathrm{E}$, Looman $\mathrm{M}$, Laouri $\mathrm{M}$, et al., Burden of illness of diabetic macular edema: literature review, Curr Med Res Opin, 2010;26:1587-97

2. Petrella RJ, Blouin J, Davies B, et al., Prevalence, Demographics, and Treatment Characteristics of Visual Impairment due to Diabetic Macular Edema in a Representative Canadian Cohort, Ophthalmol, 2012;2012:159167.

3. Williams $R$, Airey M, Baxter $H$, et al., Epidemiology of diabetic retinopathy and macular oedema: a systematic review, Eye (Lond), 2004;18:963-83.

4. Yau JW, Rogers SL, Kawasaki R, et al., Global prevalence and major risk factors of diabetic retinopathy, Diabetes Care, 2012;35:556-64. Ciulla TA, Amador AG, Zinman B, Diabetic retinopathy and diabetic macular edema: pathophysiology, screening, and novel therapies, Diabetes Care, 2003;26:2653-64.

6. Romero-Aroca P, Targeting the pathophysiology of diabetic macular edema, Diabetes Care, 2010;33:2484-5.

7. Montero JA, Ruiz-Moreno JM, Intravitreal inserts of steroids to Montero JA, Ruiz-Moreno JM, Intravitreal inserts of steroids to
treat diabetic macular edema, Curr Diabetes Rev, 2009;5:26-32.

8. Bandello F, Berchicci L, La Spina C, et al.. Evidence for anti-

8. Banderic
VEGF treatment of diabetic macular edema, Ophthalmic Res, 2012;48(Suppl. 1):16-20.
9. Frampton JE, Ranibizumab: in diabetic macular oedema, Drugs, 2012;72:509-23.

10. Klein R, Knudtson MD, Lee KE, et al., The Wisconsin Epidemiologic Study of Diabetic Retinopathy XXIII: the twentyfive-year incidence of macular edema in persons with type 1 diabetes, Ophthalmology, 2009;116:497-503.

11. Bennett N, Dodd T, Flatley J, et al., Health Survey for England 1993. Social Survey Division of the Office of Population Censuses and Surveys, 1995, London, UK: HMSO

12. Ding J, Wong TY, Current epidemiology of diabetic retinopathy and diabetic macular edema, Curr Diab Rep, 2012;12:346-54.

13. Early photocoagulation for diabetic retinopathy. ETDRS report number 9. Early Treatment Diabetic Retinopathy Study Research Group, Ophthalmology, 1991;98:766-85.

14. Romero-Aroca P, Fernandez-Balart J, Baget-Bernaldiz M, et al., Changes in the diabetic retinopathy epidemiology after 14 years in a population of Type 1 and 2 diabetic patients after the new dia potes mellitus diagnosis criteria and a more strict controw the patients, J Diabetes Complications, 2009;23:229-38.

15. Photocoagulation for diabetic macular edema. Early Treatment Diabetic Retinopathy Study report number 1 . Early Treatment Diabetic Retinopathy Study research group, Arch Ophthalmol,
1985;103:1796-806

6. Bhagat N, Grigorian RA, Tutela A, et al., Diabetic macular edema: pathogenesis and treatment, Surv Ophthalmol, 2009;54:1-32.

17. Miller EC, Capps BE, Sanghani RR, et al., Regulation of igf-I signaling in retinal endothelial cells by hyperglycemia, Invest Ophthalmol Vis Sci, 2007;48:3878-87.

18. Sakamoto T, [Cell biology of hyalocytes], Nihon Ganka Gakkai Zasshi, 2003;107:866-82; discussion 83

19. Spranger J, Osterhoff M, Reimann M, et al., Loss of the antiangiogenic pigment epithelium-derived factor in patients with angiogenic eye disease, Diabetes, 2001;50:2641-5.

20. Murakami T, Yoshimura N, Structural changes in individua retinal layers in diabetic macular edema, I Diabetes Res, 2013;2013:920713.

21. Bresnick GH, Diabetic maculopathy. A critical review highlighting diffuse macular edema, Ophthalmology, 1983;90:1301-17.

22. Browning DJ, Altaweel MM, Bressler NM, et al., Diabetic macular edema: what is focal and what is diffuse?, Am J macular edema: what is focal and what

23. Cunha-Vaz J, Diabetic macular edema, Eur J Ophthalmol 1998;8:127-30. 


\section{Diabetic Macular Oedema}

24. Quinn CJ, Cystoid macular edema, Optom Clin, 1996;5:111-30. 25. Sivaprasad S, Gupta B, Crosby-Nwaobi R, et al., Prevalence of diabetic retinopathy in various ethnic groups: a worldwide perspective, Surv Ophthalmol, 2012;57:347-70

26. White $\mathrm{NH}$, Sun W, Cleary PA, et al., Effect of prior intensive therapy in type 1 diabetes on 10-year progression of retinopathy in the DCCT/EDIC: comparison of adults and adolescents, Diabetes, 2010;59:1244-53.

27. Peto T, Tadros C, Screening for diabetic retinopathy and diabetic macular edema in the United Kingdom, Curr Diab Rep, 2012;12:338-45.

28. Kirkizlar E, Serban N, Sisson JA, et al., Evaluation of telemedicine for screening of diabetic retinopathy in the veterans health administration, Ophthalmology, 2013;120:2604-10.

29. Mansberger SL, Gleitsmann K, Gardiner S, et al., Comparing the Effectiveness of Telemedicine and Traditional Surveillance in Providing Diabetic Retinopathy Screening Examinations: A Randomized Controlled Trial, Telemed I E Health, 2013;19:942-8

30. Techniques for scatter and local photocoagulation treatment of diabetic retinopathy: Early Treatment Diabetic Retinopathy Study Report no. 3. The Early Treatment Diabetic Retinopathy Study Research Group, Int Ophthalmol Clin, 1987;27:254-64.

31. Dorin $\mathrm{G}$, Evolution of retinal laser therapy: minimum intensity photocoagulation (MIP). Can the laser heal the retina without harming it?, Semin Ophthalmol, 2004:19:62-8.

32. Bhagat $N$, Zarbin $M$, Use of subthreshold diode micropulse aser for treating diabetic macular edema, contemp Ophthalmol, 2004;3:1-5

33. Dorin G, Subthreshold and micropulse diode laser photocoagulation, Semin Ophthalmol, 2003;18:147-53.

34. Zur D, Loewenstein A, Combination therapy for diabetic macular edema, J Ophthalmol, 2012;2012:484612.

35. Grigorian R, Bhagat N, Lanzetta P, et al., Pars plana vitrectomy for refractory diabetic macular edema, Semin ophthalmol, 2003;18:116-20.

36. Laidlaw DA, Vitrectomy for diabetic macular oedema, Eye (Lond), 2008;22:1337-41.

37. Mason JO, 3rd, Colagross CT, Vail R, Diabetic vitrectomy: risks, prognosis, future trends, Curr Opin Ophthalmol, 2006;17:281-5.

38. Figueroa MS, Contreras I, Noval S, Surgical and anatomical outcomes of pars plana vitrectomy for diffuse nontractional
oution diabetic macular edema, Retina, 2008:28:420-26.

39. Diabetic Retinopathy Clinical Research Network Writing C, Haller JA, Qin H, et al., Vitrectomy outcomes in eyes with diabetic macular edema and vitreomacular traction, Ophthalmology, 2010;117:1087-93 e3.

40. Lee SS, Ghosn C, Yu Z, et al., Vitreous VEGF clearance is increased after vitrectomy, Invest Ophthalmol Vis Sci, 2010;51:2135-8.

41. Spiteri Cornish K, Lois N, Scott N, et al., Vitrectomy with interna limiting membrane (ILM) peeling versus vitrectomy with no peeling for idiopathic full-thickness macular hole (FTMH), Cochrane Database Syst Rev, 2013;6:CD009306

42. Romero-Aroca P, Current status in diabetic macular edema treatments, World J Diabetes, 2013;4:165-9.

43. Diabetic Retinopathy Clinical Research N, Beck RW, Edwards AR, et al., Three-year follow-up of a randomized trial comparing focal/grid photocoagulation and intravitreal triamcinolone for diabetic macular edema, Arch Ophthalmol, 2009;127:245-51.

44. Pacella E, Vestri AR, Muscella R, et al., Preliminary results of an intravitreal dexamethasone implant (Ozurdex(R)) in patients with persistent diabetic macular edema, Clin Ophthalmol, 2013;7:1423-8.

45. Zucchiatti I, Lattanzio R, Querques G, et al., Intravitreal dexamethasone implant in patients with persistent diabetic macular edema, Ophthalmologica, 2012;228:117-22.

46. Messenger WB, Beardsley RM, Flaxel Cl, Fluocinolone acetonide intravitreal implant for the treatment of diabetic macular edema, Drug Des Devel Ther, 2013;7:425-34.

47. Campochiaro PA, Brown DM, Pearson A, et al., Sustained delivery fluocinolone acetonide vitreous inserts provide benefit for at least 3 years in patients with diabetic macular edema, Ophthalmology, 2012:119:2125-32.

48. Campochiaro PA, Nguyen QD, Hafiz G, et al., Aqueous levels of fluocinolone acetonide after administration of fluocinolone acetonide inserts or fluocinolone acetonide implants, Ophthalmology, 2013;120:583-7.

49. Silva PS, Sun JK, Aiello LP, Role of steroids in the management of diabetic macular edema and proliferative diabetic retinopathy, Semin Ophthalmol, 2009;24:93-9.

50. Isaac DL, Abud MB, Frantz KA, et al., Comparing intravitreal triamcinolone acetonide and bevacizumab injections for the treatment of diabetic macular oedema a randomized doubleblind study, Acta Ophthalmol, 2012:90:56-60.

51. Lim JW, Lee HK, Shin MC, Comparison of intravitreal bevacizumab alone or combined with triamcinolone versus triamcinolone in diabetic macular edema: a randomized triamcinolone in diabetic macular edema. a randomich

52. Elman MJ, Bressler NM, Qin H, et al., Expanded 2-year follow-up of ranibizumab plus prompt or deferred laser or triamcinolone plus prompt laser for diabetic macular edema, Ophthalmology, 2011;118:609-14.

53. Lang GE, Long-term safety and efficacy of ranibizumab $0.5 \mathrm{mg}$ in patients with diabetic macular oedema of the RESTORE extension study, Diabetologia, 2012;55(Suppl. 885 Abstract 192).

54. Mitchell P, Bandello F, Schmidt-Erfurth U, et al., The RESTORE study: ranibizumab monotherapy or combined with laser versus laser monotherapy for diabetic macular edema, Ophthalmology, 2011;118:615-25.

55. Mitchell P, Bressler NM, Tolley K, et al., Patient-reported visual function outcomes improve following ranibizumab treatment in patients with vision impairment due to diabetic macular edema patients with vision impairment due to diabetic mach

56. Rauser ME, Intravitreal ranibizumab for diabetic macula edema with prompt vs deferred laser treatment: 3 -year randomized trial results, Invest Ophthalmol Vis Sci, 2013; ARVO Meeting Abstracts June 162013 54:212.

57. Nguyen QD, Brown DM, Marcus DM, et al., Ranibizumab for diabetic macular edema: results from 2 phase III randomized trials: RISE and RIDE, Ophthalmology, 2012;119:789-801.

58. Lang GE, Berta A, Eldem BM, et al., Two-Year Safety and Efficacy of Ranibizumab $0.5 \mathrm{mg}$ in Diabetic Macular Edema: Interim Analysis of the RESTORE Extension Study, Ophthalmology، 2013:120:2004-12

59. Mitchell P, Annemans L, Gallagher M, et al., Cost-effectiveness of ranibizumab in treatment of diabetic macular oedema (DME) causing visual impairment: evidence from the RESTORE trial,
Br J Ophthalmol, 2012;96:688-93

60. Prunte C, Extended Follow-up of Patients With Macular Edema due to Retinal Vein Occlusion (Diabetic Macular Edema) (RETAIN), Annual Meeting of the American Academy of Ophthalmology Subspeciality Day -Retina, New Orleans, US, 16 November 2013. Available at: http://www.aao.org/pdf/AAOSub_2013_RET_Syllabus. pdf (accessed 10 December 2013).

61. Arevalo JF, Lasave AF, Wu L, et al., Intravitreal bevacizumab plus grid laser photocoagulation or intravitreal bevacizumab or grid laser photocoagulation for diffuse diabetic macular edema: results of the Pan-american Collaborative Retina Study Group at 24 months, Retina, 2013;33:403-13.

62. Diabetic Retinopathy Clinical Research N, Scott IU, Edwards AR, et al., A phase II randomized clinical trial of intravitreal bevacizumab for diabetic macular edema, Ophthalmology, 2007:114:1860-67.

63. Rajendram R, Fraser-Bell S, Kaines A, et al., A 2-year prospective randomized controlled trial of intravitreal bevacizumab or laser therapy (BOLT) in the management of diabetic macular edema: 24-month data: report 3, Arch Ophthalmol 2012;130:972-9

64. Roche Avastin summary of product characteristics, 2013. Available at: http://www.medicines.org.uk/EMC/ medicine/15748/SPC/Avastin+25mg+ml+concentrate +for+solution+for+ infusion/\#PRODUCTINFO (accessed 14 November 2013).

65. Do DV, Nguyen QD, Boyer D, et al., One-year outcomes of the DA VINCI Study of VEGF Trap-Eye in eyes with diabetic macular edema, Ophthalmology, 2012;119:1658-65.

66. Bayer, Clinicaltrials.gOV VEGF Trap-Eye in Vision Impairment Due to DME (VIVID-DME), 2011; NCT01331681 (accessed 10 December 2013)

67. Bayer, Clinicaltrials.gov: Study of Intravitreal Administratio of VEGF Trap-Eye (BAY86-5321) in Patients With Diabetic Macular Edema (VISTA DME), 2011; NCT01363440 (accessed 10 December 2013).

68. Cunningham ET, Jr, Adamis AP, Altaweel M, et al., A phase Il randomized double-masked trial of pegaptanib, an antivascular endothelial growth factor aptamer, for diabetic macular edema, Ophthalmology, 2005:112:1747-57.

69. Ohji M, Ishibashi T, REVEAL Study Group, Efficacy and safety of ranibizumab $0.5 \mathrm{mg}$ as monotherapy or adjunctive to laser versus laser monotherapy in Asian patients with visual impairment due to diabetic macular edema: 12 -month results of the REVEAL study, Invest Ophthalmol Vis Sci, 2012;53 ARVO E-abstract 4664.

70. Varma A, Baseline Predictors of improvement in self-reported visual function following treatment with ranibizumab in patients with diabetic macular edema [RIDE and RISE], Inves Ophthalmol Vis Sci, 2013; ARVO Meeting Abstracts June 16 2013;54:2281.

71. Clinicaltrials.gov: Efficacy and Safety of Ranibizumab in Two 'Treat and Extend' Treatment Algorithms Versus Ranibizumab As Needed in Patients With Macular Edema and Visual Impairment Secondary to Diabetes Mellitus (RETAIN), 2010;NCT01171976:http://Clinicaltrials.gov/show/NCT01171976 (accessed 28 August 2013).

72. Klein R, Klein BE, Moss SE, et al., The Wisconsin epidemiologic study of diabetic retinopathy. IV. Diabetic macular edema, ophthalmology, 1984;91:1464-74.

\section{Box: Definition of Study Name Acronyms}

BOLT: Bevacizumab or Laser Therapy Study; DA VINCI: A Double-Masked, Randomized, Controlled Study of the Safety, Tolerability and Biological Effect of Repeated Intravitreal Administration of VEGF Trap-Eye in Patients With Diabetic Macular Edema; DRCRNet: Diabetic Retinopathy Clinical Research Network; ETDRS: Early Treatment Diabetic Retinopathy Study; FAME: Fluocinolone Acetonide for Diabetic Macular Edema; PACORES: Pan-American Collaborative Retina Study Group; RESOLVE: Safety and Efficacy of Ranibizumab in Diabetic Macular Edema; RESTORE: Ranibizumab Monotherapy or Combined with Laser vs. Laser Monotherapy for Diabetic Macular Edema; RETAIN: Extended Follow-up of Patients With Macular Edema due to Retinal Vein Occlusion (Diabetic Macular Edema); REVEAL: Efficacy and Safety of Ranibizumab (Intravitreal Injections) in Patients With Visual Impairment Due to Diabetic Macular Edema; RIDE: A Study of Ranibizumab Injection in Subjects With Clinically Significant Macular Edema With Center Involvement Secondary to Diabetes Mellitus; RISE: A Study of Ranibizumab Injection in Subjects With Clinically Significant Macular Edema With Center Involvement Secondary to Diabetes Mellitus; VISTA: Study of Intravitreal Administration of VEGF Trap-Eye (BAY86-5321) in Patients With Diabetic Macular Edema; VIVID: Efficacy and Safety of VEGF Trap Eye in Diabetic Macular Edema With Central Involvement. 